\title{
Cloud Service Providers Ranking Based on Service Delivery and Consumer Experience
}

\author{
Shyam S. Wagle \\ University of Luxembourg \\ 6, Rue R. Coudenhove-Kalergi \\ Luxembourg City, Luxembourg \\ Email: shyam.wagle.001@student.uni.lu
}

\author{
Mateusz Guzek \\ University of Luxembourg \\ 6, Rue R. Coudenhove-Kalergi \\ Luxembourg City, Luxembourg \\ Email: mateusz.guzek@uni.lu
}

\author{
Pascal Bouvry \\ University of Luxembourg \\ 6, Rue R. Coudenhove-Kalergi \\ Luxembourg City, Luxembourg \\ Email: pascal.bouvry@uni.lu
}

\begin{abstract}
Searching of the appropriate cloud services according to consumers' requirements is becoming a complex task, as the number of cloud service providers (CSPs) that offer similar kind of cloud services increases. Service level agreements (SLAs) are commitments of CSPs to their cloud users, but there are only a few simplistic verification mechanisms which ensure that CSPs are delivering cloud services according to service committed. We propose a CSP ranking model based on service delivery measurements and user experience. To rank and select the appropriate CSPs, an intuitionistic fuzzy group decision making is used, as it can include both measurable and non-measurable factors. It also provides the position of each CSP on the basis of particular SLA parameter which helps cloud users to select the CSP according to their specific requirements.
\end{abstract}

Index Terms-CSP Ranking; Service Measurement; Consumer Experience; Group Decision

\section{INTRODUCTION}

With the increasing number of cloud service providers (CSPs), selecting the appropriate cloud services according to requirements of users is a complex and tedious job. CSPs commit their service offer to the customers through Service Level Agreement (SLA). SLA is composed of different Quality of Service (QoS) rules, which are obligations that have to be followed by CSPs [1]. In many cases, CSPs offer similar or identical characteristics of services which makes more complex for cloud users to choose services according to their exact requirements. Major challenge of cloud users nowadays is the practical difficulty in trusted and objective assessment of the fulfillment of SLA terms offered by CSPs.

The current techniques and tools are more suitable to quantify functional properties than non-functional properties of the SLA attributes for measurement. Practically, non-functional SLA attributes depend mainly on the user's perceptions which are not easy to assess due to their complexities, vagueness, and the involvement of ill-structured information [2]. We propose an integration of an auditor module (two cloud auditors of different nature: internal auditor (auditor ${ }_{i n t}$ ) and external auditor $\left(\right.$ auditor $\left._{\text {ext }}\right)$ ) that measures the services delivered by CSPs. Cloud users provide their assessment according to their user experience. The opinions of cloud auditors measurement and users are expressed in linguistic terms for the performance rating of each criteria. Our proposed model ranks the cloud providers in terms of all the SLA attributes in cloud com- puting as well as in terms of particular SLA attributes (like in terms of Availability, Reliability, Performance, Cost and Security) which will be very helpful to the users to choose the appropriate CSP according to their requirements. The paper is organized as follows: Section II describes the related works in CSP ranking and service selection. Section III provides the proposed framework for CSP ranking in the basis of selected SLA attributes. The ranking algorithm used and calculation of CSP ranking for CSP recommendation are presented in Section IV. Conclusion with planned future works are described in Section V.

\section{RELATED WORKS}

The problem of selection of the best cloud services is a part of cloud brokering process [3], which includes also decision how to compose the services to optimise certain objectives. This section does not consider the whole brokering process, but only selection and ranking of the CSPs. The optimisation of resource allocation in clouds can directly tackle multiple objectives [4], however such approaches require a recommendation system to select one of the Pareto-optimal solutions.

The selection of the best web services based on consumer's vague perception is introduced by Wang [2]. However, web or cloud services cannot be practically evaluated only on the basis of consumers' perception, because user may not receive actual service delivered by CSP due to its local problems with network connection or client device. The authors of SMICloud [5] proposed a framework for comparing and ranking cloud services based on AHP [6]. SMICloud considers only quantifiable SLA attributes defined by CSMIC (https://csmic.org). It does not consider the qualitative attributes and consumer's perception, as cloud users are not involved in decision making. CloudCmp [7] is a framework for comparison of the performance of different cloud services but it takes into account only low-level performance metrics of Cloud services such as CPU utilization and network throughput etc. To the best of our knowledge, there is no framework which selects and ranks the CSP based on both service delivered by CSPs and experiences of cloud users. 
TABLE I

THE IMPORTANCE RATING WEIGHT OF EACH SUB-CRITERIA PROVIDED BY DECISION MAKERS

\begin{tabular}{|l|l|l|l|l|l|l|l|}
\hline & \multicolumn{7}{|c|}{ Decision Makers } \\
\hline Criteria & Sub-criteria & $A_{\text {int }}$ & $A_{\text {ext }}$ & $U_{1}$ & $U_{2}$ & $w\left(c_{j}\right)$ & $W\left(c_{j}\right)$ \\
\hline \multirow{2}{*}{ Availability (C1) } & Downtime(c11) & $\mathrm{VI}(0.0)$ & $\mathrm{VI}(0.0)$ & $\mathrm{I}(0.1)$ & $\mathrm{M}(0.1)$ & {$[0.5,0.4$} & {$[0.5,0.6]$} \\
& Loadbalancing(c12) & $\mathrm{VI}(0.0)$ & $\mathrm{VI}(0.0)$ & $\mathrm{I}(0.0)$ & $\mathrm{I}(0.2)$ & {$[0.7,0.3]$} & \\
\hline \multirow{2}{*}{ Reliability (C2) } & MTTB(c21) & $\mathrm{VI}(0.0)$ & $\mathrm{VI}(0.0)$ & $\mathrm{I}(0.0)$ & $\mathrm{I}(0.0)]$ & {$[0.7,0.3]$} & {$[0.5,0.6]$} \\
& Recoverable(c22) & $\mathrm{VI}(0.0)$ & $\mathrm{VI}(0.0)$ & $\mathrm{I}(0.0)$ & $\mathrm{M}(0.1)$ & {$[0.5,0.4]$} & \\
\hline \multirow{3}{*}{ Performance (C3) } & Latency(c31) & $\mathrm{VI}(0.0)$ & $\mathrm{VI}(0.0)$ & $\mathrm{I}(0.0)$ & $\mathrm{M}(0.0)$ & {$[0.5,0.5]$} & {$[0.5,0.6]$} \\
& Response time(c32) & $\mathrm{VI}(0.0)$ & $\mathrm{VI}(0.0)$ & $\mathrm{I}(0.1)$ & $\mathrm{I}(0.0)$ & {$[0.7,0.3]$} & \\
& Throughput (c33) & $\mathrm{VI}(0.0)$ & $\mathrm{VI}(0.0)$ & $\mathrm{VI}(0.0)$ & $\mathrm{VI}(0.0)$ & {$[0.9,0.1]$} & \\
\hline \multirow{2}{*}{ Cost (C4) } & Installation cost(c41) & $\mathrm{U}(0.1)$ & $\mathrm{U}(0.1)$ & $\mathrm{VI}(0.0)$ & $\mathrm{VI}(0.0)$ & {$[0.3,0.6]$} & {$[0.3,0.6]$} \\
& Running cost (c42) & $\mathrm{U}(0.1)$ & $\mathrm{U}(0.1)$ & $\mathrm{VI}(0.0)$ & $\mathrm{VI}(0.0)$ & {$[0.3,0.6]$} & \\
\hline \multirow{3}{*}{ Security (C5) } & Authentication(51) & $\mathrm{VI}(0.0)$ & $\mathrm{VI}(0.0)$ & $\mathrm{M}(0.1)$ & $\mathrm{M}(0.1)$ & {$[0.5,0.4]$} & {$[0.3,0.7]$} \\
& Encryption(c52) & $\mathrm{I}(0.0)$ & $\mathrm{U}(0.1)$ & $\mathrm{U}(0.1)$ & $\mathrm{U}(0.0)$ & {$[0.3,0.7]$} & \\
& Auditability(c53) & $\mathrm{VI}(0.0)$ & $\mathrm{VI}(0.0)$ & $\mathrm{M}(0.2)$ & $\mathrm{U}(0.1)$ & {$[0.3,0.6]$} & \\
\hline
\end{tabular}

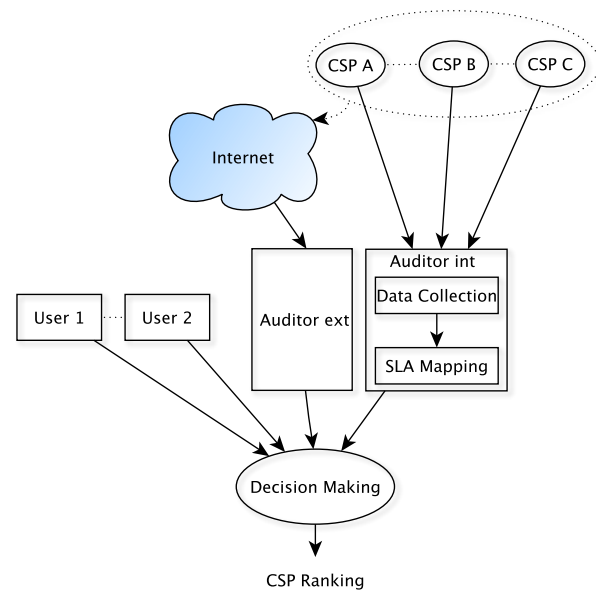

Fig. 1. Proposed Framework for CSP Ranking

\section{PROPOSED FRAMEWORK}

The proposed decision making process combines the opinions of cloud users and auditors, as presented in Fig. 1. Here, the feedback of 2 cloud users is used, but in general experiences of multiple users can be involved in to improve the quality of the sample. Similarly, there could be multiple cloud auditors for the redundancy and for extracting exact CSP status by independent actors. An internal auditor, $\left(\right.$ Auditor $_{\text {int }}$ ) monitors CSPs' performance data which could be used in together with an application performance model [8] to estimate its QoS. Auditor $_{\text {ext }}$ is a commercially available service like CloudHarmony (https://cloudharmony.com). A practical challenge in service measurement from CSP premises is that some CSPs may not allow to measure their service status on their premises. In that scenario, we lower the confidence level (i.e. high hesitation degree [9]) of that particular CSP which affects the CSP ranking. In our performance monitoring both measurable and non-measurable attributes are taken in to consideration (Table I). Non-measurable parameters are covered in group decision through cloud user service experience. Cloud service metrics play an important role in deciding how cloud services are selected and ranked. Despite that there are no standard defined SLA metrics in cloud computing, some initial works have been conducted to define the SLA metrics in cloud computing. Taking as a reference CSMIC and QoS properties for web services proposed by Maximilien et al. [10], we list some of the important SLA attributes with corresponding sub-attributes to be considered in cloud computing service monitoring (Table I). Performance, Availability, Reliability, Cost and Security are chosen as the important SLA attributes; they include measurable and non-measurable characteristics of the cloud services. Auditor ${ }_{i n t}$ can map low level measurable value to SLA parameter using mapping rules (for instance availability, $A_{v}=\frac{\text { uptime }}{\text { uptime+downtime }}$ ) if low level measured values are available. Mapping to SLA parameters from measured value depends on nature of services and types of service used. Definitions and mathematical formula proposed by Gurout et al. [1] and Padhye et al. [11] are used in parameter mapping.

\section{Cloud Service Ranking}

In this section, we introduce the basic of Instuitionistic Fuzzy sets (IFS) introduced by Atanassov et al. [9], [12], an algorithm introduced by Wang [2] to select web services based on consumer's perception and its implementaion in group decision based on auditors' service measurement and cloud users experience.

\section{A. Cloud Service Ranking Algorithm}

Let a set $\mathrm{X}=x_{1}, x_{2}, \ldots, x_{n}$ be a finite universal set. An IFS $\mathrm{A}$ on $\mathrm{X}$ is an object with the form $A=$ $\left(x, \mu_{A}(x), \nu_{A}(x)\right) \mid x \in X$ where the functions $\mu_{A}: X \rightarrow[0,1]$ and $\nu_{A}: X \rightarrow[0,1]$ assign the degree of membership and the degree of non-membership to the element $x \in X$ [9]. Functions $\mu_{A}(x)$ and $\nu_{A}(x)$ are constrained by:

$$
0 \leq \mu_{A}(x)+\nu_{A}(x) \leq 1
$$

A third parameter of IFS $\pi_{A}(x)$ which is known as the Intuitionistic Fuzzy Index (IFI) or Hesitation Degree of whether $\mathrm{x}$ belongs to A or not:

$$
\pi_{A}=1-\mu_{A}(x)-\nu_{A}(x)
$$

It is seen that for every $x \in X$ :

$$
0 \leq \pi_{A}(x) \leq 1
$$


If $\pi_{A}(x)$ has small value, knowledge about $\mathrm{x}$ is more certain and vice-versa. We apply the following algorithm to rank the CSP based on complete SLA criteria and individual criteria. We first select the evaluation criteria with different sub-criteria under each criteria. Decision makers involved in decision making use the linguistic terms [2] defined in Table II to define the importance of criteria in linguistic term. The aggregated group importance of the criterion $w\left(c_{j}\right)$ is defined as:

$$
w\left(c_{j}\right)=\left[\mu_{w}\left(c_{j}\right), \nu_{w}\left(c_{j}\right)\right]
$$

where $w\left(c_{j}\right)$ is calculated using intersection operator of IFN defined by Atanassov[12] with all the IFN value provided by decision makers.

To compare each SLA attributes from alternative CSP, we aggregate the weights of subcriteria under the same criteria to calculate $W\left(c_{j}\right)$ :

$$
W\left(c_{j}\right)=w\left(c_{i 1}\right) \cap w\left(c_{i 2}\right) \cap \ldots . \cap w\left(c_{i n}\right)
$$

where $i$ belongs to the same SLA criteria. $W\left(c_{j}\right)$ is the aggregated weight of the importance of all sub-critera to criteria.

Decision makers evaluate each of the alternatives and gives the corresponding score for each alternatives. Let the $D_{k}(k=1, \ldots, q)$ decision makers employ the symbolic linguistic terms defined in second column of Table II to evaluate the performance of cloud provider under each criterion $\left(c_{j}\right)(j=1 ; 2 ; \ldots ; n)$ which is expressed in the form of the matrix:

$$
X=\left[x_{i j}^{k}\right]\left[\begin{array}{cccc}
x_{11}^{k} & x_{12}^{k} & \ldots & x_{1 n}^{k} \\
x_{21}^{k} & x_{22}^{k} & \ldots & x_{2 n}^{k} \\
\ldots & \ldots & \ldots & \ldots \\
x_{m 1}^{k} & x_{m 2}^{k} & \ldots & x_{m n}^{k}
\end{array}\right]
$$

where $k$ is number of decision makers, $n$ is the number of selection criteria and $m$ is the number of alternative CSPs.

Using Max-Min-Max composition (T) defined by Biswas [13] and De et. al [14], $Z^{k}\left(C S P_{i}\right)$ is calculated from $x_{i j}^{k}$ and $w\left(c_{j}\right)$ [2]:

$$
Z^{k}\left(C S P_{i}\right)=T\left(x_{i j}^{k}, w\left(c_{j}\right)\right)
$$

The average of $Z^{k}\left(C S P_{i}\right)$ is as denoted as $Z\left(C S P_{i}\right)$, to aggregate the score of the decision makers. To evaluate the performance and rank the order of alternatives, the score functions [2]; $S_{w}\left(C_{j}\right)$ and $S\left(C S P_{i}\right)$ is calculated as follows:

$$
\begin{gathered}
S_{w}\left(C_{j}\right)=\mu_{w}\left(C_{j}\right)-\pi_{w}\left(C_{j}\right) * \nu_{w}\left(C_{i}\right) \\
S_{C S P}\left(C S P_{i}\right)=\mu_{z}\left(C S P_{i}\right)-\pi_{z}\left(C S P_{i}\right) * \nu_{z}\left(C S P_{i}\right)
\end{gathered}
$$

The Highest value of $S_{C S P}\left(C S P_{i}\right)$ gives the highest rank and lowest value gives lowest rank for that particular SLA parameter. Finally, external auditors measurements needs to be mapped to IFS input. According to service commitment by cloud provider, we define multiple breaking points considering service credit offered by cloud provider in case of service violation (e.g. see Amazon-EC2 SLA template(http://aws.amazon.com/ec2/sla). We set minimum value
TABLE II

LINGUISTIC TERMS FOR THE IMPORTANCE OF A CRITERIA AND PERFROMANCE RATING

\begin{tabular}{|l|l|l|l|}
\hline Importance of Criteria & $\begin{array}{l}\text { Performance Rat- } \\
\text { ing }\end{array}$ & IFNs & $\begin{array}{l}\text { Measured } \\
\text { Value }\end{array}$ \\
\hline Very unimportant (VU) & Very Poor (VP) & {$\left[\begin{array}{lll}0.1 & 0.9-\pi\end{array}\right]$} & $<$ min $_{\text {value }}$ \\
\hline Unimportant (U) & Poor (P) & {$\left[\begin{array}{lll}0.3 & 0.7-\pi\end{array}\right]$} & min $_{\text {value }}$ \\
\hline Medium (M) & Fair (F) & {$\left[\begin{array}{lll}0.5 & 0.5-\pi\end{array}\right]$} & th $_{\text {value }}$ \\
\hline Important (I) & Good(G) & {$\left[\begin{array}{lll}0.7 & 0.2-\pi\end{array}\right]$} & max value \\
\hline Very Important (VI) & Very Good (VG) & {$\left[\begin{array}{lll}0.9 & 0.1-\pi\end{array}\right]$} & $>$ max value \\
\hline I do not know (N) & I do not know (N) & {$\left[\begin{array}{ll}0.0 & 0.0\end{array}\right]$} & $\begin{array}{l}\text { Data not re- } \\
\text { ceived }\end{array}$ \\
\hline
\end{tabular}

$\left(\min _{\text {value }}\right)$, maximum value $\left(\max _{\text {value }}\right)$ and threshold value $\left(t h_{\text {value }}\right)$ to compare SLA offer of cloud providers. If a measured value is greater than $\max _{\text {value }}$, it is interpreted as Very Good (VG). If measured value is less than min $_{\text {value }}$ it is interpreted as very poor (VP). If cloud provider does not allow to collect the service status or some parameters are missing from cloud provider, it is interpreted as I do not know (N) (Table II).

\section{B. Cloud Service Provider(CSP) Ranking}

We select the best cloud provider from three alternative cloud providers; $C S P_{A}, C S P_{B}$ and $C S P_{C}$ (Fig.1). They are assessed by a group of 4 decision makers ( 2 cloud auditors and 2 cloud users), based on defined SLA criteria (Table I). According to the importance of each criteria, cloud auditors and cloud users assigns the importance of weight of each parameter. All of the weight ratings provided by decision makers are aggregated to common weight using Eq.4. For the calculation, we have randomly selected certain weight for each decision makers based on their nature. For example most of the SLA parameters are very important for cloud auditors except Cost whereas Cost is the most important for the cloud users. In a deployed framework, a real weight for each attribute should be defined by decision makers and obtained by means of user surveys or based on service status measured by auditors. According to the service status of the CSP, and according to the service experienced by cloud user, they assign the performance rating for each alternative CSP (See Table III). The performance matrix $X_{i j}$ is created using decision makers input presented in Table III and weight rating of each criteria $W\left(c_{j}\right)$ are presented in Table I, $Z\left(C S P_{i}\right)$ is calculated to assign the scoring value for each criteria using Eq.6 in Table IV. The corresponding values of $Z\left(C S P_{i}\right)$ with each SLA criteria $C_{j}$ signifies the group decision provided by 4 decision makers for 3 alternative CSPs. To rank the CSP, average value of all the criteria is calculated for each CSP. Scoring value of each SLA criteria is calculated in Table $\mathrm{V}$ which provides the scoring for each SLA parameter under different CSPs. On the basis of scoring value, cloud user selects the appropriate CSP according to his/her requirement in each SLA parameter.

\section{Result Discussion}

The final calculated result is presented in Table IV. $C S P_{A}$ is the highest ranked and the ranking of the cloud providers is 
TABLE V

SCORING VALUE For CSP BASEd ON SLA PARAMTERS $S_{W\left(C_{j}\right)}$

\begin{tabular}{|c|c|c|c|c|c|c|c|c|c|c|c|c|c|c|}
\hline \multicolumn{5}{|c|}{$C S P_{A}$} & \multicolumn{5}{|c|}{$C S P_{B}$} & \multicolumn{5}{|c|}{$C S P_{C}$} \\
\hline $\mathrm{C} 1$ & $\mathrm{C} 2$ & C3 & $\mathrm{C} 4$ & $\mathrm{C} 5$ & C1 & $\mathrm{C} 2$ & C3 & $\mathrm{C} 4$ & $\mathrm{C} 5$ & C1 & $\mathrm{C} 2$ & C3 & $\mathrm{C} 4$ & $\mathrm{C} 5$ \\
\hline 0.207 & 0.146 & 0.208 & 0.207 & 0.146 & 0.208 & 0.260 & 0.146 & 0.208 & 0.209 & 0.146 & 0.208 & 0.138 & 0.130 & 0.202 \\
\hline
\end{tabular}

TABLE III

PERFORMANCE MATRIX

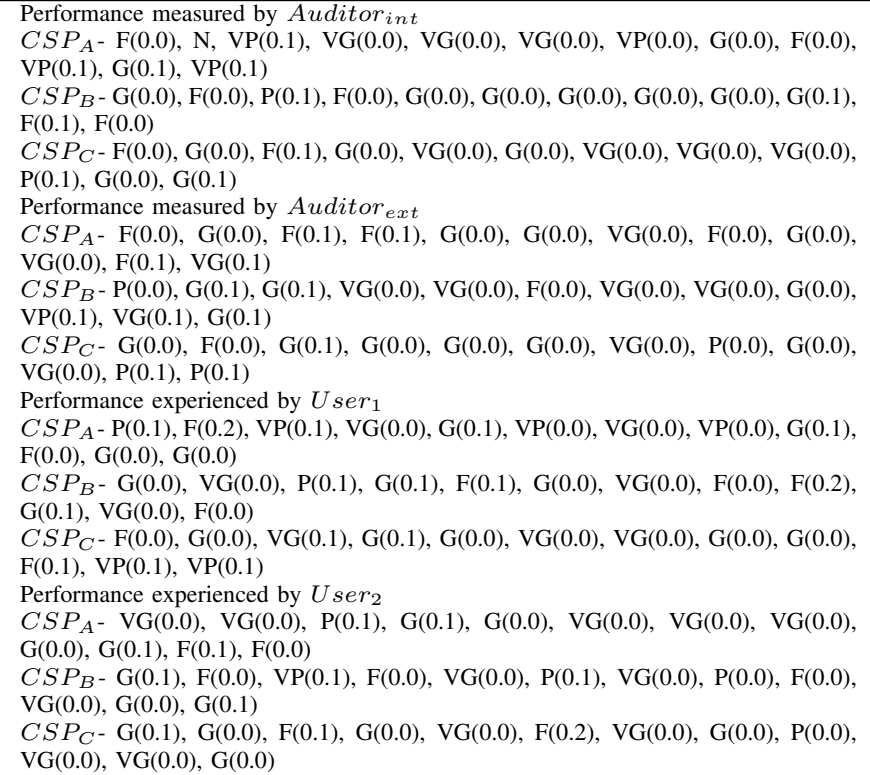

TABLE IV

DECISION MATRIX $Z\left(C S P_{i}\right)$

\begin{tabular}{|c|c|c|c|}
\hline & $C S P_{A}$ & $C S P_{B}$ & $C S P_{C}$ \\
\hline C1 & {$[0.249,0.06]$} & {$[0.20,0.07]$} & {$[0.25,0.05]$} \\
C2 & {$[0.249,0.06]$} & {$[0.21,0.07]$} & {$[0.25,0.05]$} \\
C3 & {$[0.299,0.06]$} & {$[0.20,0.07]$} & {$[0.25,0.05]$} \\
C4 & {$[0.249,0.05]$} & {$[0.21,0.07]$} & {$[0.25,0.05]$} \\
C5 & {$[0.20,0.08]$} & {$[0.20,0.09]$} & {$[0.25,0.06]$} \\
\hline Avg & {$[0.25,0]$} & {$[0.16,0]$} & {$[0.24,0]$} \\
\hline
\end{tabular}

$C S P_{A}>C S P_{C}>C S P_{B}$. Table $\mathrm{V}$ presents the final score of the each SLA parameter based on the group decision of three alternative CSPs. Cloud user can further choose the cloud service according to his/her requirements. For example, if cloud user is more interested in Availability, his/her preference will be towards $C S P_{B}$ rather than other cloud providers. Similarly, if a cloud user wants cheaper services, his/her preference will be $C S P_{C}$. The proposed model is simplifying the the complexity and reducing doubts associated with selecting commercial CSPs with respect to users' requirements.

\section{CONCLUSion AND Future Works}

The proposed framework is a recommendation system that facilitates selection of the appropriate cloud service provider. It supports both measurable and non-measurable attributes of cloud services of CSPs. The recommendation of cloud provider is based on the entire SLA requirements as well as on the particular SLA parameters required by the cloud users. Real performance monitoring of CSPs' by auditors process creates additional degree of trust and reliability for the cloud users. Future works involve testing of the proposed framework with real performance monitoring and users experience. This work is also a part of a larger framework for SLA-assured brokering and CSP certification [15].

\section{ACKNOWLEDGMENT}

S. S. Wagle would like to thank LAST-JD program for financially supporting to perform this research. This work is partially funded from Luxembourg National Research Fund (FNR) IShOP (POLLUX/13/IS/6466384) project.

\section{REFERENCES}

[1] T. Gurout, S. Medjiah, G. D. Costa, and T. Monteil, "Quality of service modeling for green scheduling in clouds," Sustainable Computing: Informatics and Systems, vol. 4, no. 4, pp. 225 - 240, 2014.

[2] P. Wang, "Qos-aware web services selection with intuitionistic fuzzy set under consumers vague perception," Expert Systems with Applications, vol. 36, no. 3, Part 1, pp. 4460 - 4466, 2009.

[3] M. Guzek, A. Gniewek, P. Bouvry, J. Musial, and J. Blazewicz, "Cloud brokering: Current practices and upcoming challenges," Cloud Computing, IEEE, vol. 2, no. 2, pp. 40-47, Mar 2015.

[4] M. Guzek, J. E. Pecero, B. Dorronsoro, and P. Bouvry, "Multi-objective evolutionary algorithms for energy-aware scheduling on distributed computing systems," Applied Soft Computing, vol. 24, pp. 432-446, 2014.

[5] S. Garg, S. Versteeg, and R. Buyya, "Smicloud: A framework for comparing and ranking cloud services," in Utility and Cloud Computing (UCC), 2011 Fourth IEEE International Conference on, Dec 2011, pp. $210-218$.

[6] S. Thomas, "Theory and applications of analytic network process." Pittsburgh, PA: RWS Publications, 2005.

[7] A. Li, X. Yang, S. Kandula, and M. Zhang, "Cloudcmp: Comparing public cloud providers," in Proceedings of the 10th ACM SIGCOMM Conference on Internet Measurement, ser. IMC '10, 2010, pp. 1-14.

[8] M. Guzek, S. Varrette, V. Plugaru, J. E. Pecero, and P. Bouvry, "A holistic model of the performance and the energy efficiency of hypervisors in a high-performance computing environment," Concurrency and Computation: Practice and Experience, vol. 26, no. 15, pp. 2569-2590, 2014.

[9] K. Atanassov and G. Gargov, "Interval valued intuitionistic fuzzy sets," Fuzzy Sets Syst., vol. 31, no. 3, pp. 343-349, Jul. 1989.

[10] E. Maximilien and M. Singh, "A framework and ontology for dynamic web services selection," Internet Computing, IEEE, vol. 8, no. 5, pp. 84-93, Sept 2004.

[11] J. Padhye, V. Firoiu, D. Towsley, and J. Kurose, "Modeling tcp throughput: A simple model and its empirical validation," SIGCOMM Comput. Commun. Rev., vol. 28, no. 4, pp. 303-314, Oct. 1998.

[12] K. T. Atanassov, "Intuitionistic fuzzy sets," Fuzzy Sets Syst., vol. 20, no. 1 , pp. 87-96, Aug. 1986.

[13] R. Biswas, "Intuitionistic fuzzy relations. bulletin for studies and exchange of fuzziness and its applications," BUSEFAL, vol. 70, p. 2229, july 1997.

[14] S. K. De, R. Biswas, and A. R. Roy, "An application of intuitionistic fuzzy sets in medical diagnosis," Fuzzy Sets and Systems, vol. 117, no. 2, pp. $209-213,2001$

[15] S. Wagle, "Sla assured brokering (sab) and csp certification in cloud computing," in Utility and Cloud Computing (UCC), 2014 IEEE/ACM 7th International Conference on, Dec 2014, pp. 1016-1017. 